\title{
REPRESENTAÇÕES AMBIENTAIS EM MANUAIS DIDÁTICOS ELABORADOS PARA PRODUÇÃO DE HORTAS ESCOLARES
}

\author{
Fernanda Marques da Silva ${ }^{1}$; Elenise da Silva Pereira²; Leticia Azambuja Lopes ${ }^{3}$
}

\section{RESUMO}

Atividades que proporcionam a confecção de hortas nas escolas é frequente no ensino de Ciências, e também são utilizadas exaustivamente como um dos pilares da Educação Ambiental. Problematizar estas atividades realizadas e observar a confecção de uma horta nas aulas de Ciências, estimulou o objetivo desta pesquisa: a análise de manuais para confecção de hortas. A metodologia utilizada está vinculada à análise cultural problematizando as representações presentes nestes manuais, os quais, a partir dos resultados, demonstram linguagens que representam e transmitem aspectos antropocêntricos, nomeiam vegetais como úteis e não úteis, ensinam como matar insetos e moluscos. Estes resultados geraram questionamentos: É isso que queremos ensinar aos nossos alunos? Conclui-se que a prática da horta não deve ser abolida do ensino, mas sim repensada enquanto importante recurso para a Educação Ambiental.

Palavras-chave: Ensino de Ciências; Hortas escolares; Antropocentrismo.

\section{ENVIRONMENTAL REPRESENTATIONS IN DIDACTIC MANUALS PRODUCED FOR THE PRODUCTION OF SCHOOL GARDENS}

\begin{abstract}
Activities that provide gardening in schools are frequent in science teaching, and are also used extensively as one of the pillars of Environmental Education. Problematizing these activities and observing the preparation of a vegetable garden in Science classes stimulated the objective of this research: the analysis of manuals for gardening. The methodology used is linked to the cultural analysis, problematizing the representations present in these manuals, which, from the results, demonstrate languages that represent and transmit anthropocentric aspects, name vegetables as useful and not useful, teach how to kill insects and mollusks. These results have raised questions: Is this what we want to teach our students? It is concluded that the practice of the garden should not be abolished teaching, but rather rethought as an important resource for Environmental Education.
\end{abstract}

1 Graduada. Universidade Luterana do Brasil (ULBRA). E-mail: fmarques028@gmail.com.

2 Graduada. Programa de Pós-Graduação em Ensino de Ciências e Matemática da Universidade Luterana do Brasil (PPGECIM/ULBRA). CAPES. E-mail: elenise.spg@gmail.com. 3 Doutora. E-mail: leazambuja@gmail.com. 
Keywords: Science teaching; School gardens; Anthropocentrism.

\section{Introdução}

Há uma certa popularização de trabalhos nos quais a horta é utilizada como método para aprendizagem de uma alimentação saudável, ou como prática para que os alunos possam ter contato com a natureza. A prática das hortas escolares ainda tem o viés interdisciplinar, pois segundo Fetter et al. (2006), a horta pode ser um instrumento importante para a construção de conhecimento nas áreas das Ciências Naturais, Educação Alimentar e Educação Ambiental. Bizzo (2010), também relata que a horta escolar é uma das práticas que auxilia na transgressão da estrutura disciplinar, que busca 0 conhecimento sob diferentes óticas e utilizasse de vários sistemas de referências e linguagens.

Sobre o plantio de hortaliças, Oliveira e Soares (2014), relatam que "as atividades de contato com o solo, tais como mexer na terra, plantar e colher, não só representam uma ótima atividade física, como também, um aprendizado saudável e criativo" (p. 1). Borges e Freitas (2013) caracterizam a horta como uma atividade extracurricular a ser desenvolvida pelos alunos em turno contrário à escola. A construção de hortas escolares está presente no ensino de Ciências e na Educação Ambiental, além de ser referida como atividade interdisciplinar é definida também como produtora da relação aluno e natureza. Segundo Effting (2007), "a interação dos alunos com a horta pode proporcionar o contato com a natureza, possibilitando o trabalho de questões pertinentes e que provocam a reflexão crítica" (p. 21).

Os dois manuais analisados ensinam como confeccionar uma horta na escola ou em sua casa, mas estes materiais ensinam determinados modos não muito ecológicos de lidar com a natureza. Eles classificam vegetais em "não úteis e úteis", ensinam como "matar" insetos e moluscos, e ainda propagam a ideia de que a natureza existe para nos satisfazer. Com isso, a horta acaba transmitindo aspectos antropocêntricos e se tornando uma atividade que merece ser problematizada. A análise dos dois materiais se torna importante, pois eles estão dentro das salas de aula em contato com os alunos.

A análise desses manuais seguirá os Estudos Culturais, pois a prática da horta se tornou uma atividade naturalizada, ou seja, ela não é questionada, 
deixando o entendimento de que são práticas perfeitas. Mas, ao ler estes materiais que ensinam os estudantes a confeccionarem uma horta, é perceptível os problemas que estes possuem, pois os dois propagam aspectos antropocêntricos. Livros, propagandas publicitárias, documentários, revistas, manuais, entre outros, são produções culturais que mesmo não sendo voltadas à escola, possuem efeitos sobre as identidades dos sujeitos que estão lá e em suas ações (WORTMANN, 2001).

Segundo Costa, et al. (2003), os Estudos Culturais "vão surgir em meio ás movimentações de certos grupos sociais que buscam se apropriar de instrumentais, de ferramentas conceituais, de saberes que emergem de suas leituras do mundo" (p. 37). Os Estudos Culturais além de problematizarem temas naturalizados do nosso cotidiano, enfatizam a importância de se analisar o conjunto de produção cultural de uma determina sociedade. A cultura não pode mais ser entendida apenas como uma acumuladora de saberes, ela precisa ser estudada e compreendida, tendo consciência de tudo que está relacionado a ela, e o papel que ela assumiu em todos os aspectos da vida social (COSTA, SILVEIRA e SOMMER 2003).

O conceito de representação é amplamente utilizado nos Estudos Culturais. Dentro dos estudos, a representação é umas das práticas centrais na produção de cultura e uma mediadora, os seus significados são produzidos e iram circular por meio de diversos processos (WORTMANN, 2001). Para Hall (1997) a representação irá ligar o significado e a linguagem com a cultura, pois representar é a parte do processo onde o significado é produzido e estendido entre os integrantes da cultura. Esses manuais que acabam se tornando mediadores do conhecimento estão carregados de representações, com significados e linguagens que precisam ser questionados.

Para Stuart Hall (1997) lidar com a representação é admitir que o significado se encontra tanto nos objetos como nas pessoas, nas ideias e eventos da realidade. A linguagem será como um espelho que refletirá o verdadeiro significado que os mesmos já têm, pois já existem no mundo, ela funciona como um sistema de representação, e nele serão utilizados símbolos, palavras, sinais, sons, entre outros. Utilizamos do sistema de representação da nossa cultura para construir conceitos, significados e para relatar outras culturas. O significado das palavras e a sua representação são pontos 
importantes na análise dos manuais. Muitos se utilizam dos significados para governar, estruturar ou moldar os indivíduos, fazendo com que estes aceitem esses significados sem contestá-los. Wortmann (2001) afirma que:

\footnotetext{
Por tudo isso é que se torna necessário atentar, para os processos, os códigos, as estruturas, as convenções e as práticas em que se produzem diferentes sistemas de significação em instâncias de produção cultural, como o cinema, a publicidade, a pintura, a fotografia, as diferentes formas de literatura [...] (p. 158).
}

A representação está presente fortemente nas análises culturais, as autoras Amaral e Conceição (2013), afirmam que, essa presença se justifica através do entendimento "de que o significado que damos às coisas é consequência do modo como as representamos, e esses significados estão sendo produzidos, reproduzidos e disputados em diversos lugares e práticas sociais" (p. 3). A análise cultural, nada mais é do que um método de investigação das atividades humanas, na comunicação, mídia, sociedade e cultura. Kellner (2001), diz que os Estudos Culturais "enxerga todas as formas de cultura da mídia e de comunicação como dignas de exame e crítica" (p. 53). Com a perspectiva dos Estudos Culturais, dos conceitos de representação e análise cultural, temos o embasamento teórico para análise dos manuais de confecção de horta.

\section{Percurso metodológico}

Esta pesquisa foi realizada no âmbito do Programa Institucional de Bolsas de Iniciação à Docência, do curso de Ciências Biológicas (PIBID/Ulbra) em turmas do Ensino Fundamental, onde ocorreu a confecção de uma horta, e percebeu-se que essa atividade não é questionada dando a entender que não possui problemas. Mediante as práticas observadas no PIBID e no estágio de observação, houve a estimulação para problematizar a horta no ensino de Ciências, através da análise de manuais de confecção de hortas.

O presente trabalho analisou dois manuais: Manual para escolas: a escola promovendo hábitos alimentares saudáveis (IRALA; FERNADEZ, 2001) e Projeto Horta Solidária: Cultivo de hortaliças (MAKISHIMA ET AL, 2005), sob a ótica metodológica dos Estudos Culturais. Tais manuais são utilizados amplamente, são de fácil acesso e estão disponíveis gratuitamente na internet. 
Os manuais recebem o apoio do Ministério da Saúde e Ministério da Agricultura, Pecuária e Abastecimento. O primeiro foi realizado pela Universidade de Brasília, Faculdade de Ciências da Saúde e Departamento de Nutrição. O segundo foi realizado pela Embrapa Meio Ambiente junto com a Faculdade de Jaguariúna.

\section{Resultados}

O manual Projeto Horta Solidária: Cultivo de hortaliças (MAKISHIMA ET AL, 2005), realizado pela Universidade de Brasília, se inicia na explicação sobre como preparar a área, ensina o seguinte: "roçar ou capinar o que estiver crescendo e que não seja útil; quebrar os torrões com a enxada" (p. 8). Após esses procedimentos deve-se regar a área frequentemente e esperar alguns dias, após isso propõe a "retirar o mato que nasceu" (p. 9). Na página 10, o Cultivo de hortaliças ensina os cuidados que devemos ter com a horta, e um deles é "capinar ou arrancar as plantas indesejáveis; verificar se as plantas estão com pragas ou outros problemas". Diante dessas informações é perceptível como a horta acaba transmitindo noções antropocêntricas. Sobre o antropocentrismo, Grün (2007) nos fala que "o Homem é considerado o centro de tudo e todas as demais coisas no universo existem única e exclusivamente em função dele" (p. 44). No plantio de mudas para se ter os produtos desejáveis, aconselham a capinar, arrancar aquilo que não é útil - mas, a questão é: útil para quem? Para o ser humano. No ensino de Ciências nos deparamos com situações como essa. Daisy Oliveira (1992) afirma isso:

\footnotetext{
Entre as classificações da Natureza, é comum que o critério utilizado seja a importância para o homem. Assim os mamíferos são classificados em "selvagens ou domésticos", os insetos em "úteis e nocivos", as plantas que não são cultivadas, por não terem importância econômica, são ditas "daninhas" [...] As flores são ditas ter o papel de enfeitar a Natureza e os frutos, obviamente, de ter a função de nos alimentar e proporcionar prazer (p. 10).
}

Segundo Carola e Constante (2015), essa apropriação da natureza acaba se firmando nas disciplinas escolares. Os autores afirmam que:

De forma implícita ou explícita, todas as disciplinas expressam concepções de natureza e cultura; e no decorrer do século XX, as disciplinas nos ensinaram a ver e conhecer o mundo natural como 
algo a ser explorado, dominado, manipulado ou mesmo preservado para atender um interesse exclusivo da sociedade humana (p. 364).

Essas concepções da natureza começaram a ser divulgadas mais fortemente no século $\mathrm{XX}$, mas vemos que permanecem até os dias atuais, como exemplo os dois manuais aqui apresentados. Eles caracterizam como "pragas" na horta os organismos como lagartas, besouros, caramujos, formigas, entre outros. Segundo o Cultivo de hortaliças (2005), eles são considerados pragas porque "raspam, sugam, comem e fazem furos nas folhas, hastes, frutas e raízes" (p. 11). A denominação "praga" só Ihes é dada porque segundo esse trabalho, eles "destroem" o que é útil para nós. Mas esses organismos ditos "pragas" estão apenas se alimentando e sobrevivendo conforme a sua ecologia. $O$ trabalho propõe que esses organismos sejam exterminados por inseticidas ou que tenham seus ovos (larvas) esmagados. Além disso, indicam outros químicos para matar moscas, besouros, percevejos, e para "controlar" (esse é o termo utilizado) lesmas, caramujos pequenos e o caramujo gigante africano. No caso das lesmas e caramujos pequenos, o Cultivo de hortaliças aconselha a utilização de uma "isca atrativa: ao entardecer, colocar entre as plantas, faixas de pano embebidas em mistura de 1 litro de leite e 4 litros de água; de manhãzinha, coletar os bichos e matá-los. O caramujo gigante africano deve ser coletado à noite e ao amanhecer, colocando-o num balde contendo salmoura (água saturada de sal) ou água com detergente ou sabão" (p. 13).

É importante considerar que quando se joga sal em um molusco, este provoca a saída de água de seu corpo, através do processo de osmose. 0 molusco morre então por desidratação, devido à perda excessiva de água. Como já foi citado antes, a horta é uma prática da educação ambiental que tem por objetivo conscientizar o ser humano que ele faz parte da natureza, que ele deve preservá-la e viver em harmonia com os seres vivos. Como ensinar isso aos nossos alunos, escolhendo como prática uma atividade que vai fazer com que eles tenham que matar seres vivos? Como ensinar com uma prática que leva organismos à morte por desidratação? Que atividade de educação ambiental é essa em que temos que escolher quem vive e quem morre?

O Projeto Horta Solidária: Cultivo de hortaliças (2005) mostra que, principalmente, insetos e moluscos são prejudiciais para a horta. Freitas et al 
(2006), em seu trabalho titulado "Insetos como Indicadores de Conservação da Paisagem" nos diz que:

Em países de clima temperado, diversos invertebrados, particularmente insetos, vêm sendo usados com sucesso em estudos de bioindicação em ambientes terrestres [...]. Dentre alguns táxons que têm sido usados com sucesso podem ser destacados muitos insetos, entre eles libélulas, borboletas, formigas, abelhas e algumas famílias de besouros (p. 3).

O autor quando fala em formigas, salienta a sua importância ecológica, explicando que essas interagem com outros organismos em todos os níveis tróficos. As formigas possuem grande atuação em relações de mutualismo e antagonismo. Freitas et al (2006), ainda, relata que quando elas estão "forrageando na vegetação, as formigas predadoras podem diminuir as taxas de herbivoria e aumentar o sucesso reprodutivo das plantas" (p. 9). E, ainda, atuam como dispersoras, influenciando diretamente na distribuição das populações de plantas.

Os besouros foram citados no Projeto Horta Solidária: Cultivo de Hortaliças como "pragas". Esses insetos apresentam grande distribuição geográfica, sendo o grupo mais abundante de insetos. Alimentam-se de diversas formas, uma delas é a detritívora, ou seja, eles se alimentam de partículas que são o produto da decomposição de animais ou vegetais, atuam como decompositores e são classificados como indicadores biológicos. Segundo Marinoni; Dutra (1997), os besouros herbívoros estarão presentes em hábitats em estágios iniciais de sucessão ou mais degradados; já os besouros que atuam como decompositores, são encontrados em ambientes em estados mais avançados de sucessão, por exemplo, nas florestas maduras.

As "ervas daninhas" aparecem nos manuais de horta como invasoras. Esses trabalhos as descrevem como espécies que irão competir com as hortaliças, prejudicando-as. Conceitos antropocêntricos são utilizados para esse tipo de vegetação: Cruz (1979) diz que ervas daninhas são plantas "sem valor econômico ou que competem, com o homem, pelo solo" (p.23). Fisher (1973) também as classifica como "plantas que interferem com os objetivos do homem em determinada situação".

A Universidade Federal de Santa Catarina, em uma oficina com o tema "plantas indicadoras", apresentam algumas espécies que são comumente 
consideradas daninhas, mas que, na verdade, são de grande importância como, por exemplo, temos a espécie Aristida pallens, conhecida como Barbade-bode. Segundo o material da oficina disponibilizado na internet, essa planta indica a presença de solos com baixa fertilidade. O popularmente chamado de Picão preto (Galinsoga parviflora) é dito como planta indicadora do excesso de nitrogênio, e aparece em solos com deficiência de micronutrientes.

Esses são alguns dos inúmeros seres que são considerados pelos manuais voltados para a organização de hortas como prejudiciais a nós. Mas, se formos pesquisar, iremos encontrar resultados de que essas espécies possuem importância ecológica e atuam no equilíbrio do meio ambiente. Essa visão de que são prejudiciais foi criada pelo ser humano, que tem como característica querer dominar tudo ao seu redor. Esta ideia errônea se confirma segundo a pesquisa de Vitcoskidaitix (2010), que relata que o ser humano não se sente parte da natureza: "se o Homem não faz parte da natureza e essa existe apenas em função dele, parece natural que ele possa usufruir de tudo que ela oferece" (p. 8-9).

O Manual para escolas: a escola promovendo hábitos alimentares saudáveis (IRALA; FERNADEZ, 2001), indica 22 espécies de vegetais para o plantio, dizendo que esses vegetais são "as principais hortaliças", ou seja, não dão importância para outros vegetais, pois não são "úteis" ao ser humano como estes já citados. A visão de utilitarismo que esse material transmite, afirma os aspectos antropocêntricos que estes manuais apresentam. Esse tipo de material será utilizado na Educação Ambiental, ou seja, os alunos estarão aprendendo em sala de aula quais animais são "úteis" e quais não são. Kindel (2012), explica que:

\footnotetext{
A natureza tem sido compreendida como a serviço do ser humano, como se ele não fizesse parte dela. Essa visão, por considerar o homem como centro de tudo, foi também apropriada pela escola, mais especificadamente pelo ensino de Ciências, que busca ensinar as crianças sobre a "utilidade" dos animais e dos outros seres vivos (vegetais, bactérias, entre outros) (p. 60).
}

Para cuidar da horta o Manual para escolas, explica que "a horta tem que ser mantida limpa, as ervas daninhas e outras sujidades devem ser retiradas diariamente com a mão" (p.7). O termo sujidade, segundo o minidicionário Aurélio (2002), significa "qualidade do que é sujo, imundície, 
sujeira". Estabelecer o que é "sujo" na horta não tem sentido, pois a natureza não produz sujeira, não produz lixo. A terra é composta pela matéria orgânica, essa matéria é decomposta pelos microrganismos e é formado o húmus, que tem grande valor nutritivo e faz com que a terra seja fértil. Se formos tirar as "sujidades" da terra, estaríamos retirando: galhos, folhas, frutas, componentes que podem estar presentes em uma horta. Mas, esses componentes são fundamentais para o surgimento da matéria orgânica, o que comprova que a ideia de retirar as "sujidades" da terra não tem sentido.

O manual afirma que a terra utilizada no cultivo das hortaliças possui muitos microrganismos que "se não forem retirados do alimento, podem provocar doenças graves" (p.12). Essa afirmação é confusa, pois enquanto que autores afirmam como o contato com a terra é bom para os alunos, o manual defende a ideia de que os microrganismos encontrados na terra serão prejudiciais à nossa saúde. Na conclusão do Manual, explicam que "a higienização correta das hortaliças garante que as sujeiras da terra saiam das hortaliças e, consequentemente, o risco de diarreia, dores de cabeças e muitas doenças sejam muito menor para todos" (p.21). Dos microrganismos encontrados na terra, os mais abundantes são os fungos, que agem como decompositores da matéria orgânica. As doenças causadas por microrganismos, geralmente, têm relação com a água e não com a terra. Doenças diarreicas como febre tifoide, cólera, verminoses, entre outras, estão relacionadas com a água de consumo humano (MACÊDO, 2001). Segundo Tundisi (2005), a contaminação do ambiente aquático ocorre devido à descarga de resíduos humanos, nestes podemos encontrar uma gama de diferentes patógenos que podem ocasionar doenças gastrointestinais.

Com isso, é perceptível que a terra não possui "sujeira", e que as doenças estão relacionadas com as ações humanas. O manual representou a natureza como algo sujo, ao afirmar que esta possui "sujidades". Esse conteúdo entrará nas salas de aulas e transmitirá aos alunos que a natureza produz sujeira, uma visão claramente antropocêntrica, pois sabemos que o único ser vivo que polui é o ser humano.

\section{Conclusões}


Os resultados obtidos indicam que ocorre diversos equívocos relacionados à tentativa de utilização destes materiais como sensibilizadores no contexto de incentivar a prática de construir uma horta escolar para que os alunos possam ter contato com a natureza, pois foi perceptível que esses manuais não estão ensinando os nossos alunos a preservar a natureza, tendo em vista a linguagem utilizada, bem como as representações da natureza que apareceram nas análises. Por exemplo, na agricultura o termo "praga" é amplamente utilizado, mas não devemos, dentro do contexto da Educação Ambiental, ensinar aos alunos matar certos animais porque são pragas. $O$ conceito de "praga" deve ser problematizado e repensado nos termos de "serviços ambientais" em que estão inseridos estes organismos, bem como nos termos da agricultura predatória que temos hoje, com a implementação de monoculturas que degradam ecossistemas, levando a quebra em teias tróficas importantes. Sem contar os efeitos deletérios do uso indiscriminado de agrotóxicos, os quais desenvolvem uma cadeia destrutiva de eventos que provavelmente são quase impossíveis de solucionar à curto prazo. Não é viável ensinar aos nossos alunos que existem plantas úteis e não úteis, mandá-los escolher quem vive e quem morre e ensiná-los que a terra produz sujeira, isso não é Educação Ambiental. Temos o dever de educar que todo ser vivo deve ser respeitado. O ser humano não pode atribuir-se o direito de exterminar outros seres ou explorá-los, o ser humano não pode atribuir-se da natureza como se ela fosse sua e que essa existe apenas para seu benefício.

As críticas aqui elaboradas são significativas para o pensamento construtivo e elaboração de novas ideias, novas sugestões, que venham a contribuir para a Educação Ambiental. A importância de criticar esses materiais é evidente, não podemos deixar temas como esses entrarem em sala de aula, quando o assunto é educação tudo deve ser questionado, criticado. As práticas com horta, não devem ser abolidas, não é isso que este estudo quer afirmar, mas lançar questionamentos sobre a maneira que ela tem sido abordada e os problemas que apresentam. Práticas naturalizadas devem ser problematizadas, a consequência desse processo será uma educação melhor, mais crítica e reflexiva.

\section{Referências}


AMARAL, Marise Basso; CONCEIÇÃO, Nayara Elisa Costa. Mídia e educação: representações de natureza na publicidade. VII EPEA -Encontro Pesquisa em Educação Ambiental. Rio Claro - SP, 07 a 10 de Julho de 2013.

AURÉLIO, O mini dicionário da língua portuguesa. $4^{a}$ edição revista e ampliada do mini dicionário Aurélio. $7^{\text {a }}$ impressão - Rio de Janeiro, 2002.

BIZZO, Nélio.. Hortas em Escolas Urbanas, Complexidade e Transdisciplinariedade: Contribuições para o ensino de Ciências e para a Educação em Saúde. Dissertação de Mestrado, UFRJ, 2010.

BORGES, Lizyane Lima.; FREITAS Pedro Henrique.; Horta escolar recurso para se discutir a educação ambiental. I Seminário de Pós-Graduação em Educação para Ciências e Matemática, X Semana de Licenciatura. Anais da X Semana da Licenciatura. Jataí, GO, 2013.

CAROLA, Carlos Renato; CONSTANTE, Cátia Elaine. Antropocentrismo pedagógico e naturalização da exploração ambiental no ensino de ciências (Brasil, 1960-1970). Rev. eletrônica Mestr. Educ. Ambient., v. 32, n. 1 (2015). Disponível em: https://www.seer.furg.br/remea/article/view/5167/3277, acesso em 14 jun 2016.

CHAGAS, Genoveva. Uso de Jornais e revistas na perspectiva da representação social de meio ambiente em sala de aula. In: Reigota, M. Verde cotidiano- o meio ambiente em discussão. Rio de Janeiro: DP\&A, 1999.

COSTA, Marisa Vorraber; SILVEIRA, Rosa Hessel; SOMMER, Luiz Henrique. Estudos culturais, educação e pedagogia. Revista Brasileira de Educação. Maio/Jun/Jul/Ago, 2003.

CRUZ, L. S. P. Herbicidas em cultura de algodão. São Paulo: CATI, 1979. EFFTING, Tânia Regina. Educação ambiental nas escolas públicas: realidades e desafios. Universidade Estadual do Oeste do Paraná - Unioeste. Dissertação (Campus de Marechal Cândido Rondon. Centro de Ciências Agrárias. Programa de Pós-graduação em "latu sensu" Planejamento para o Desenvolvimento Sustentável). 2007.

FETTER, S. I. MULLER, J. SILVA, M.C. Horta escolar: Teoria e Prática para uma vida saudável. Educação ambiental na escola municipal João Mosmann/ Parobé/ RS. Ver. Bras. De Agroecologia Vol. 1 № .1, novembro, 2006.

FISCHER, H.H. Conceito de ervas daninhas. In: RODRIGUES, J.J., WILLIAN, R. D. (Eds.). Curso intensivo de controle químico de ervas daninhas. Viçosa, MG. UFG, 1973. p. 1-74.

FREITAS, André Victor Lucci et al. Insetos como Indicadores de Conservação da paisagem. In: ROCHA, Carlos Frederico Duarte da Bergalho et al. Biologia da Conservação - Essências. São Carlos / SP. Rima, 2006. P. 2-19.

GRÜN, Mauro. Ética e Educação Ambiental: a conexão necessária. 
Campinas: Papirus, 2007. (Coleção Magistério: Formação e Trabalho Pedagógico).

HALL, Stuart. The work of representation. In: Hall, Stuart. Representation: cultural representations and signifying practices. London/Thousand Oaks/New Delhi: Sage/The Open University, 1997. (Tradução Ricardo Uebel).

IRALA, Clarissa Hoffman; FERNANDEZ, Patrícia Martins. Manual para Escolas: a Escola promovendo hábitos alimentares saudáveis. FUNSAUDE/Departamento de Nutrição com o Departamento de Política de Alimentação e Nutrição da Secretária de Políticas de Saúde do Ministério da Saúde. Universidade de Brasília. Brasília, 2001.

KELLNER, Douglas. A cultura da mídia - estudos culturais: identidade e política entre o moderno e o pós-moderno. Bauru, SP: EDUSC, 2001.

KINDEL, Eunice Aitalsaia. Práticas pedagógicas em Ciêmcias: espaço, tempo e corporeidade. Erechim: Edelbra, 2012.

MACÊDO, J. A. B. Águas e Águas. São Paulo: Varela. Ed: 1. 2001.

MAKISHIMA, Nozomu et al. Projeto horta solidária: cultivo de hortaliças. Embrapa Meio Ambiente. Jaguariúna, 2005.

MARINONI, R. C. \& R. R. C. Dutra. 1997. Famílias de Coleoptera capturadas com armadilha malaise em oito localidades do Estado do Paraná, Brasil. Diversidades alfa e beta. REVISTA BRASILEIRA DE ZOOLOGIA 14 (3):751770. Ministério da Educação. A horta escolar dinamizando o currículo da escola - caderno 1. Brasília, 2009.

OLIVEIRA, Daisy Lara. O antropocentrismo no ensino de ciências. In: Revista Espaços da Escola. Unijuí: Livraria Editora Unijuí, Ano 1, n. 4, Abril/Junho de 1992. P. 08-15.

OLIVEIRA, Luan Pereira; SOARES Francisco Jeanes Silva; Impacto das atividades de projetos de hortas em escolar. PROBEX/2014 Cultivando Saúde na Escola e PROEXT/2014 Hortas - Modificando Hábitos e Cultivando Saúde. UFPB, Paraíba, 2014. p. 01.

TUNDISI, J. G. (2005). Água no século XXI: Enfrentando a escassez. Rima IIE. São Paulo Carlos.

UFSC, Universidade Federal de Santa Catarina. Plantas Indicadoras. Disponível em: http://conevajr.ufsc.br/files/2015/01/Folder-PlantasIndicadoras.pdf, acesso em 25 de Jul 2016.

VITCOSKIDAITX, Vanessa. 0 Ensino de Ciências e a visão antropocêntrica. UFRGS. Instituto de Biociências. Porto Alegre, 2010.

WORTMANN, Maria Lúcia Castagna. 0 uso do termo representação na Educação em Ciências e nos Estudos Culturais. Pro-Posições - vol. 12, N. 1 
AMBIENTE \& EDUCAÇÃO

ISSN - 1413-8638

E-ISSN - 2238-5533

v. 23, n.2, p. 349-351, 2018

(34) - março/2001. 